\title{
The Organic Composition of Carbonaceous Meteorites: The Evolutionary Story Ahead of Biochemistry
}

\author{
Sandra Pizzarello ${ }^{1}$ and Everett Shock ${ }^{1,2}$ \\ ${ }^{1}$ Department of Chemistry and Biochemistry, Arizona State University, Tempe, Arizona 85287-1604 \\ ${ }^{2}$ School of Earth and Space Exploration, Arizona State University, Tempe, Arizona 85287-1404 \\ Correspondence: pizzar@asu.edu
}

Carbon-containing meteorites provide a natural sample of the extraterrestrial organic chemistry that occurred in the solar system ahead of life's origin on the Earth. Analyses of 40 years have shown the organic content of these meteorites to be materials as diverse as kerogen-like macromolecules and simpler soluble compounds such as amino acids and polyols. Many meteoritic molecules have identical counterpart in the biosphere and, in a primitive group of meteorites, represent the majority of their carbon. Most of the compounds in meteorites have isotopic compositions that date their formation to presolar environments and reveal a long and active cosmochemical evolution of the biogenic elements. Whether this evolution resumed on the Earth to foster biogenesis after exogenous delivery of meteoritic and cometary materials is not known, yet, the selective abundance of biomolecule precursors evident in some cosmic environments and the unique L-asymmetry of some meteoritic amino acids are suggestive of their possible contribution to terrestrial molecular evolution.

\section{INTRODUCTION}

Why Meteorites are Part of the Discourse about the Origin of Life

$\mathrm{T}_{\mathrm{o}}^{\mathrm{h}}$ he studies of meteorites have long been part of investigations and discussions about the origin of life for the reason that some of these extraterrestrial bodies have reached the Earth containing abundant carbon since its accretion, provide a natural sample of abiotic organic chemistry, and may offer insights on the possible environments and physico-chemical processes that fostered biogenesis. These conditions are entirely unknown because geological and biological processes of over four billion years have long eradicated any traces of early Earth's chemistry. On the other hand, we know that life has embarked in a long evolutionary path all through its recorded history and it seems reasonable to extend to its unknown beginning the same evolutionary nature. Albeit a posteriori and without knowledge of the actual chemical steps that carried this evolution, therefore, the single assessment one can safely make about

Editors: David Deamer and Jack W. Szostak

Additional Perspectives on The Origins of Life available at www.cshperspectives.org

Copyright (C) 2010 Cold Spring Harbor Laboratory Press; all rights reserved; doi: 10.1101/cshperspect.a002105

Cite this article as Cold Spring Harb Perspect Biol 2010;2:a002105 
life's origin on the Earth is that it must have been an emergent process, through which biogenic atoms and molecules gained the complex associative and interactive states we observe in even the simplest forms of extant life. It is then easy to see why the discourse about the origins of life has been multidisciplinary, broad based, and fostered many theories, all of which, with the notable exception of the panspermia hypothesis (e.g., Crick and Orgel 1973), accept the fundamental emergent nature of life from simple molecules.

In exobiological (as well as astrobiological) terms, it has been proposed that life's fundamental evolutionary nature might have extended beyond its origin and might be rooted in the abiotic cosmochemical evolution of the biogenic elements. C, H, N, O, P, and S are known to be present as diverse and often complex organic molecules in a variety of extraterrestrial environments (Lazcano 2010) and their long cosmic history has supported the idea of a possible exobiology. However, its analytical basis comes from the study of carbon-containing meteorites that have provided the only natural sample of chemical evolution large enough for direct laboratory analyses. Uniquely, therefore, carbon containing meteorites record for us the abiotic organic chemistry that preceded life's origin and may as yet reveal whether it is realistic to assume that these or similar materials, i.e., either by direct delivery or analogy of formation, might have fostered or even inducted molecular evolution toward biogenesis.

The Early Solar System, Meteorites, and the Possible Survival of Cosmochemical Evolution

The meteorites that reach the Earth are for the most part fragments of asteroids, i.e., of those small planetesimals that orbit the Sun in great number between Mars and Jupiter. By the Titius-Bode law of a regular spacing of planets from the Sun, their orbit should be occupied by a planet; it is believed, however, that the small chunks of early solar materials reaching this area fell under the strong gravity of the already formed giant planets and were either scattered throughout or left unable to coalesce. That is how we still find them today, joined by icy objects from more distant locations of the solar system that were brought in by further dynamical evolution of giant planets' orbits (Levison et al. 2009). With their crowding, hazardous orbits, and constant collisions, all of these bodies put fragments on route to the Earth and have done so through the ages. The importance of meteorites for the study of prebiotic chemistry is a result of this failed planet formation and not just for their obvious delivery but also because many of the asteroid belt objects never had their composition drastically transformed by gravitational high temperatures and pressures as larger bodies did. Their meteoritic fragments, therefore, may carry unaltered a pristine record of early solar system chemistry as well as allow the deciphering of its cosmic history.

The meteorites that best fit this description are the carbonaceous chondrites (CCs), a primitive subgroup of stony meteorites having an elemental composition that is very similar to that of the Sun and the universe overall. As their name indicates, CCs have the distinction of containing several percent amounts $(\sim 1.5 \%-4 \%)$ of carbon, which is for the most part present as organic materials. These meteorites are aggregate rocks, i.e., consist mainly of a matrix made of packed together hydrous and anhydrous silicates that do not show signs of metamorphism or alteration by high heat. However, as part of their small planet parent bodies, CC mineralogy also shows that these rocks had experienced a liquid water phase as well as the effects of impact shocks. For example, a recent measurement of the optical activity of three CC surfaces (Arteaga et al. 2010) showed a circular birefringence bias to negative values that the authors attribute to chiral fractures and distortions in the clays following mechanical forces. The meteorites' aggregation also captured various inclusions; the chondrules, to whose name CCs owe their classification, are round beads of glassy appearance that have re-crystallized from a melt, i.e., high heat, and bring witnesses to the variety of materials and processes that must have contributed to CC parent bodies' formation (Fig. 1).

Overall, these meteorites do not seem to differ much from terrestrial rocks, a similarity 


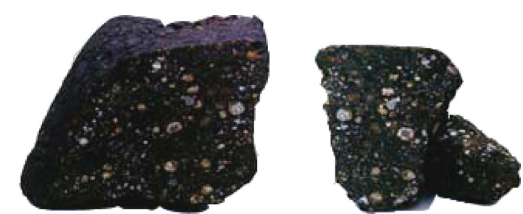

Figure 1. A CR2 meteorite stone found in the Antarctica Graves mountains (GRA 95229). The open faces show the large chondrules that characterize this family of meteorites. Chondrule and other inclusion abundance reduce the amount of matrix where organics are found to about $30 \%$ of the geology.

that has not helped their collection or preservation because, if not seen to fall and promptly collected, they easily disappear in the environment. The Murchison meteorite was exceptional in this respect because it fell at the very eve of lunar samples' return in 1969 and was analyzed directly by NASA laboratories as a possible analog of those samples. One hundred kilograms of this meteorite were recovered and have been used in 40 years of analyses for probably the most comprehensive study of any extraterrestrial organic material to date. As a result of this focus, the Murchison meteorite composition has long been considered representative not only of meteorites of the same type (Pizzarello et al. 2006) but, often (e.g., Luisi 2007), also of the capabilities of abiotic organic syntheses in general. Given our yet tentative knowledge of cosmochemical environments, it is not surprising that the latter assumption turned out to be premature and a new group of pristine meteorites found in the ice fields of Antarctica, the Renazzo-family of chondrites or CR, have been offering a novel view of the possible synthetic outcomes of abiotic chemical evolution as well as of its prebiotic relevance.

\section{BACKGROUND}

The Abiotic Organic Composition of Meteorites: Prebiotic Traits and Biochemical Counterparts

In spite of exhaustive chemical analyses, we still have a very vague idea of where Murchison organic materials are actually located vis-avis the inorganic components in the meteorite. The only successful description so far was obtained by X-ray microscopy of the meteorite surfaces after their exposure to selective staining with $\mathrm{OsO}_{4}$ vapors (Pearson et al. 2007). From these analyses, they appear to be broadly distributed within the matrix, intermixed with hydrous silicate components. As in other CCs, Murchison organic materials can be broadly described in terms of their solubility in aqueous and organic solvent systems, a practical characterization that nevertheless leaves room for missed analytical targets and the possibility of unknowns (e.g., Deamer 1985). Insoluble and soluble components represent respectively $70 \%$ and $30 \%$ of total carbon and, within their molecular range, are both very complex and fundamentally heterogeneous.

\section{Murchison Insoluble Organic Material (IOM)}

The larger portion of Murchison organic carbon is often referred to as kerogen-like because, like terrestrial kerogens, it is an insoluble macromolecular material of complex composition that is not known in much molecular detail; its average elemental abundances are $\mathrm{C}_{100} \mathrm{H}_{46} \mathrm{~N}_{10} \mathrm{O}_{15} \mathrm{~S}_{4.5}$. The bulk of the IOM can be inferred only indirectly from spectroscopy (e.g., nuclear magnetic resonance and infrared) and by decomposition studies, where it is pyrolyzed by heat or oxidized into its fragments. These analyses suggest a general structure composed of aromatic ring clusters, bridged by aliphatic chains containing $\mathrm{S}$, $\mathrm{N}$, and $\mathrm{O}$, with peripheral branching and functional groups. By transmission electron microscopy, most of the IOM appears dispersed and amorphous but $\sim 10 \%$ of it is found as selfcontained nanostructures (Fig. 2), spheres as well as tubes, of diverse elemental composition that varies from close to pure graphitic C $(>99 \%)$ to containing several percent amounts of $\mathrm{O}, \mathrm{N}$, and $\mathrm{S}$. The IOM also contain minute amounts of "exotic" carbon, so called because it was likely formed in the envelopes of stars prior to the formation of the solar system.

On the whole, the large compositional heterogeneity of the IOM as well as the diversity of its phases strongly suggest that this material is the complex end product of cosmochemical regimes and environments that varied greatly. 
S. Pizzarello and E. Shock

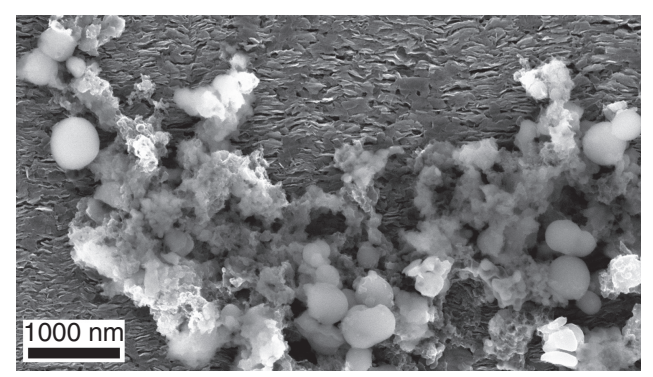

Figure 2. Scanning electron microscope image of the GRA 95229 acid residue showing an abundance of submicron-sized spherical carbonaceous particles. The particles are solid, single, and agglomerated with the largest close to $500 \mathrm{~nm}$ in diameter. The residue is deposited onto a carbon planchette and imaged with $5 \mathrm{kV}$ electrons and current of $98 \mathrm{pA}$ (reprinted with express permission from Laurence Garvie).

On the other hand, in spite of being insoluble in acids and solvents, the IOM can free several individual compounds under conditions of high temperature and pressure similar to those of terrestrial hydrothermal vents $\left(300^{\circ} \mathrm{C}, 100 \mathrm{MPa}\right)$ (Yabuta et al. 2007). These are mainly a variety of aromatic and heteroaromatic hydrocarbons but also smaller noncondensed molecular species and a suite of alkyl dicarboxylic acids up to $\mathrm{C}_{18}$ chain length. In addition, the hydrothermolysis changed the IOM's chiral response to the Soai autocatalytic reaction in that it displayed a statistical R-chiral bias prior to the treatment but not afterwards (Kawasaki et al. 2006), suggesting that some chiral species are present in Murchison IOM but cannot be detected at the molecular level. These experiments show that portions of the IOM macromolecular structure can be modified at the molecular level, exchange species with the soluble organic pool, and possibly represent materials caught in flux between aggregation states. We may also assume that, were meteoritic materials exposed to hydrothermal conditions or prolonged exposure to water upon their fall, IOM release might have made an important contribution to the organic pool of the early Earth when CCs delivered an estimated $1 \%-3 \%$ of their weight in carbon during the early impact period (Mautner et al. 1995).

\section{Murchison Soluble Organic Compounds}

The soluble organic compounds of the Murchison meteorite make up an abundant and diverse group of well over a thousand molecular species that vary from smaller water-soluble compounds such as amino acids and polyols up to 30-carbon-long nonpolar hydrocarbons extracted only with solvents (Table 1). As their large number indicates, they are also present in multiple isomeric forms up to the limit of their solubility. This diversity is observed throughout most of the various compound types and is often a sign of their indigeneity because it contrasts starkly with the structural and functional selectivity displayed in biochemistry. It has been analyzed in particular detail for Murchison amino acids. For example, all the possible $\alpha$-amino alkylamino acids up to sevencarbon were identified in Murchison extracts based on the reference of synthesized standards and several eight- and nine-carbon homologous species could also be easily recognized by chromatography-mass spectroscopy on the basis of their spectra even if their standards were not available. Similar large abundances of N-substituted, cyclic, $\beta$-, $\gamma$-, $\delta$-, and $\varepsilon$-amino acids were also found and the total number of meteoritic amino acids can be placed at over one hundred. In contrast, the whole of terrestrial protein is made up of just 20 amino acids.

Within this overall diversity, several components of Murchison's organic suite have identical counterparts in the biosphere. Eight of the meteorite amino acids are also found in proteins (glycine, alanine, proline, valine, leucine, isoleucine, aspartic acid, and glutamic acid) and numerous other compounds are encountered in terrestrial metabolisms, as shown in Table 1 . A very interesting similarity with biochemical traits was found in a group of chiral amino acids not present in terrestrial proteins, the 2-methyl 2-amino acids, which display in Murchison L-enantiomeric excesses (ee) that, if not as large, have the same configuration $(\mathrm{L}-)$ of terrestrial protein. The $e e$ were first discovered in the diastereomers of the sevencarbon 2-amino 2,3-dimethylbutaoic acid (Fig. 3) (Cronin and Pizzarello 1997) and were 
The Organic Composition of Carbonaceous Meteorites

Table 1. Classes of organic compounds in the Murchison meteorite.

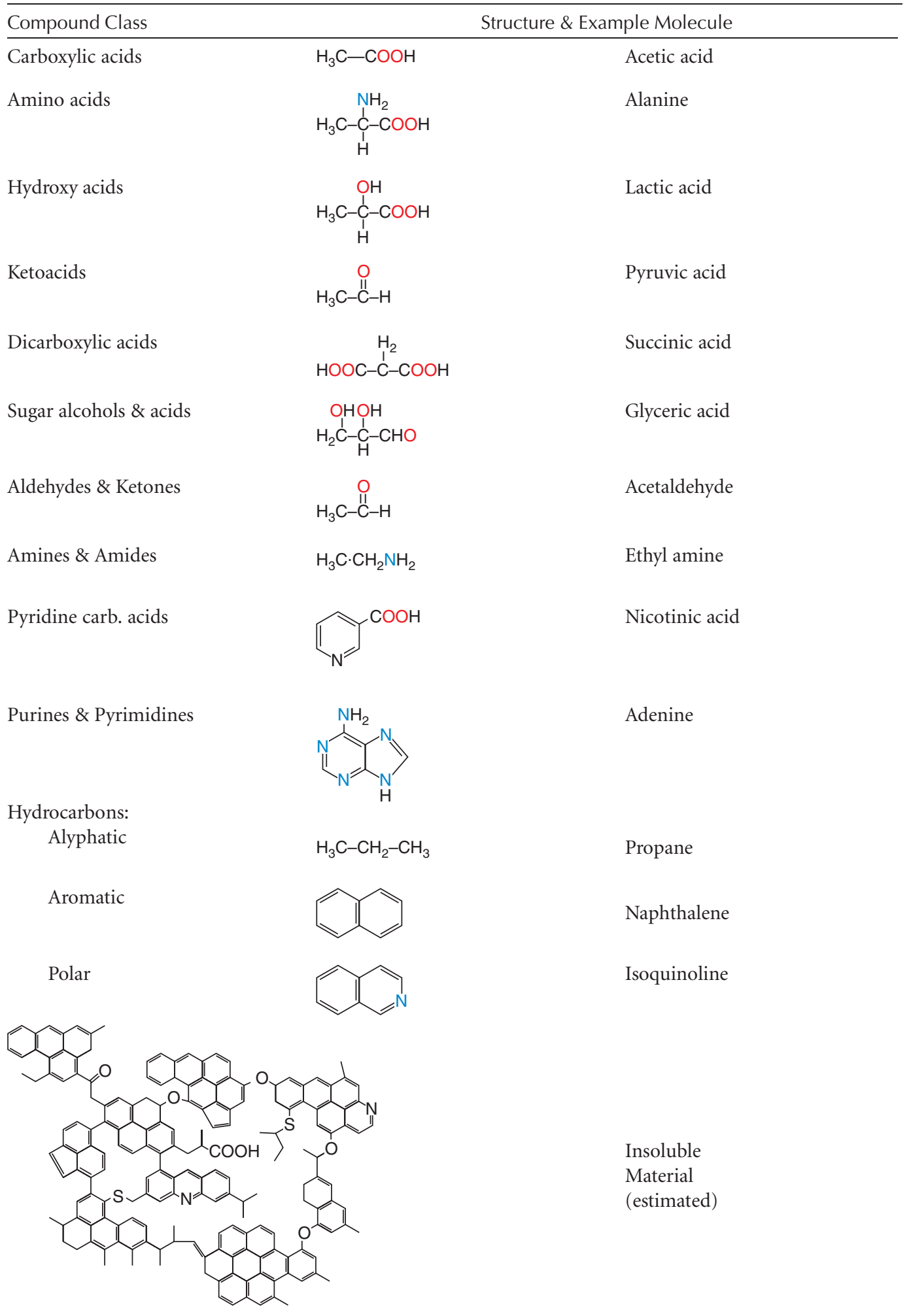


S. Pizzarello and E. Shock
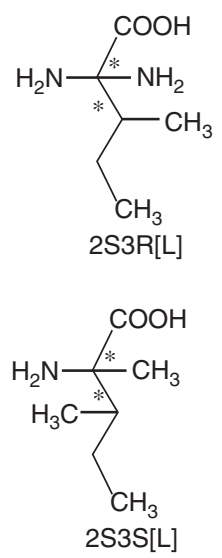

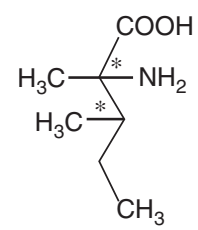

2R3S[D]

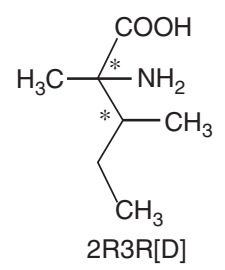

$(\mathrm{L})$

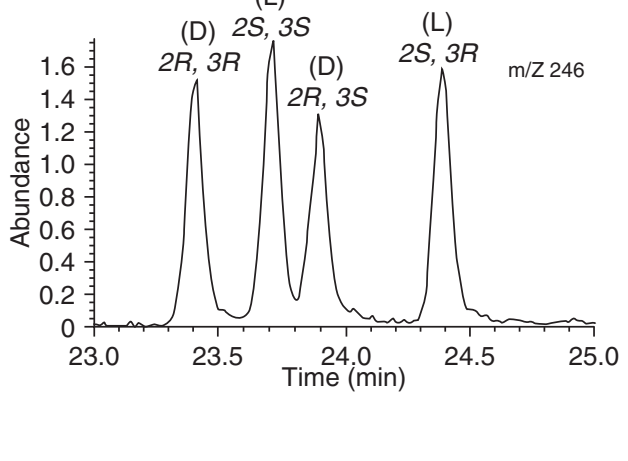

Figure 3. Chemical structure and chromatographic elution of the Murchison 2-amino 2,3-dimethylbutyric acid diastereomers.

later established for the whole homologous series of these chiral compounds up to eightcarbon long; their magnitude varies within the meteorite and is largest, up to $18 \%$, for isovaline (2-methyl-2-aminobutyric acid). As the biochemical structures and functions of all life today are dependent upon the exclusive chiral homogeneity of their polymers, it appears reasonable to assume that a homochirality, albeit of unknown origin, was also essential to the origin and/or evolution of life. The ee of meteorites represent the only case so far of molecular asymmetry ever measured outside the biosphere and their indigeneity is supported by compound specific carbon-, and hydrogen isotopic data obtained for $\mathrm{D}^{-}$, and L-isovaline enantiomers (Pizzarello et al. 2003; Pizzarello and Huang 2005).

Overall, the study of Murchison has disclosed detailed insights on the capabilities and possible range of abiotic syntheses in cosmochemical environments. We have learned that this abiotic chemistry can form organic materials of considerable complexity and include compounds similar or identical to biomolecules. Particularly captivating is the finding of chiral asymmetry in abiotic amino acids and, although less defined at the molecular level, the fact that some macromolecular and inorganic phases of the meteorite show signs of optical activity is intriguing as well. Considered as a whole, these data support the conclusion that molecular chiral asymmetry preceded biochemistry.

Nevertheless, these studies also leave many questions unanswered as to the prebiotic potential of an organic suite of Murchison-like composition. In fact, the large heterogeneity of Murchison organic inventories and the apparent randomness involved in their formation led to question the means and opportunities by which such a diverse mixture of molecules, a majority of which are thermodynamically stable end products (e.g., carboxylic acids and hydrocarbons), could find an evolutionary path toward the selectivity and functional specificity displayed by even the simplest biochemistry.

\section{RECENT RESULTS}

\section{The CR Antarctica Finds}

Recorded falls of carbonaceous chondrites have been few (37 to date, since the first registered in 1806) and this record is needed, because these meteorites resemble terrestrial rocks, are porous in nature, and quickly disappear into the environments if not spotted soon. For the same reason, their organic analyses have also become increasingly limited in scope with their years of terrestrial residence, due to the ease with which CCs acquire biochemical contaminants. Fortunately, several of the meteorites recovered in 
The Organic Composition of Carbonaceous Meteorites

Antarctica are found unspoiled because of the unique shelter of the glaciers, where falling meteorites are quickly covered by snow, remain buried within the ice, and resurface only when the ice sheets, flowing toward the sea, encounter the obstacle of a mountain.

Renazzo family of meteorites make up a recent classification (CR) of several Antarctic "finds" that have petrology closely similar to that of the Renazzo meteorite, a CC that fell in 1864 and long remained unclassified. Two CR2 ${ }^{1}$ meteorites (the GRA95229 and LAP02342 ${ }^{2}$ ) were analyzed recently for the major groups of organic compounds known to be present in the Murchison meteorite (Pizzarello et al. 2008; Pizzarello and Holmes 2009) and have shown an organic composition that differs dramatically from that of Murchison and, in fact, from any seen before in carbonaceous meteorites (Fig. 4). Their organic suite is composed mainly of water-soluble compounds, between which $\mathrm{N}$-containing amino acids and amines are predominant. Ammonia is the single largest component of the suite, whereas hydrocarbons and carboxylic acids are only minor components. Novel were also the abundant distributions found within CR2 amino acids, where the shorter chain-length molecules of a homologous series, e.g., glycine, alanine, and $\alpha$-amino isobutyric acid, are overabundant compared to longer chain species and, in effect, account for most of these compounds' abundance. Several reactive compounds are found in these meteorites as well, such as aldehydes, tertiary amines, and the hydroxy amino acids serine, threonine, allothreonine, and tyrosine (Pizzarello and Holmes 2009); the latter two groups of compounds were never detected in Murchison.

Another difference between CR2 and CM meteorites is found in their respective content of enantiomerically enriched chiral molecules. In CR2s, the same amino acid species having

\footnotetext{
${ }^{1}$ The number represents a classification of petrographic type and estimates asteroidal secondary processes (were $2<1$ ).

${ }^{2}$ The acronyms stand for the names of the Antarctica locations where the meteorites were found: Graves mountain and LaPaz ice fields, respectively.
}

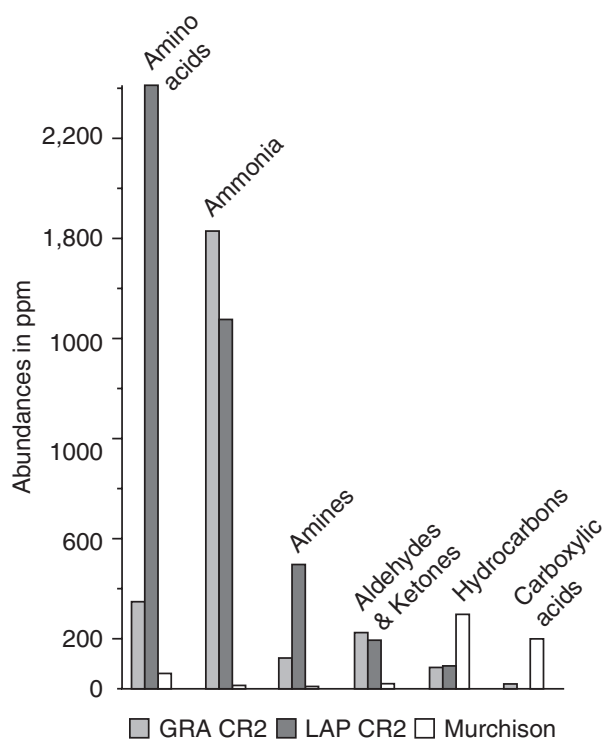

Figure 4. Comparative plot of major soluble organic compound abundances in the Murchison and CR2 meteorites (GRA 95229 and LAP 02342 shown).

ee in CMs display this trait to less extent (GRA95229) or not at all (LAP02342), whereas the abundance distribution of some of the meteorites' diastereomer amino acids allowed the inference of an original asymmetry of their precursor aldehydes (Pizzarello et al. 2008). This somewhat indirect reasoning concerns the diastereomers of the amino acid isoleucine and can be explained as follows. The molecule [2-amino3-methylpentanoic acid, $\mathrm{CH}_{3} \mathrm{CH}_{2}$ $\left.\mathrm{C}^{*} \mathrm{H}\left(\mathrm{CH}_{3}\right)-\mathrm{C}^{*} \mathrm{H}\left(\mathrm{NH}_{2}\right)-\mathrm{COOH}\right]$ contains two chiral centers $\left(\mathrm{C}^{*}\right)$ and can be present as two different compounds (depending on the possible distribution of the methyl branching along the alkyl chain), each with two enantiomers, i.e., the pairs of D-, L-isoleucine (ile) and D-, L-alloisoleucine (allo) (called diastereomers and shown schematically in Fig. 5B). Only L-ile is present in terrestrial proteins, whereas all four diastereomers are found in meteorites.

A possible reaction for the formation of amino acids in meteorites is the addition of $\mathrm{HCN}$ to ketones and aldehydes in the presence of water and ammonia (Fig. 5A) (e.g., Peltzer and Bada 1978). Although producing an asymmetric carbon in most cases (and therefore a chiral molecule), this type of synthesis is 
S. Pizzarello and E. Shock

A
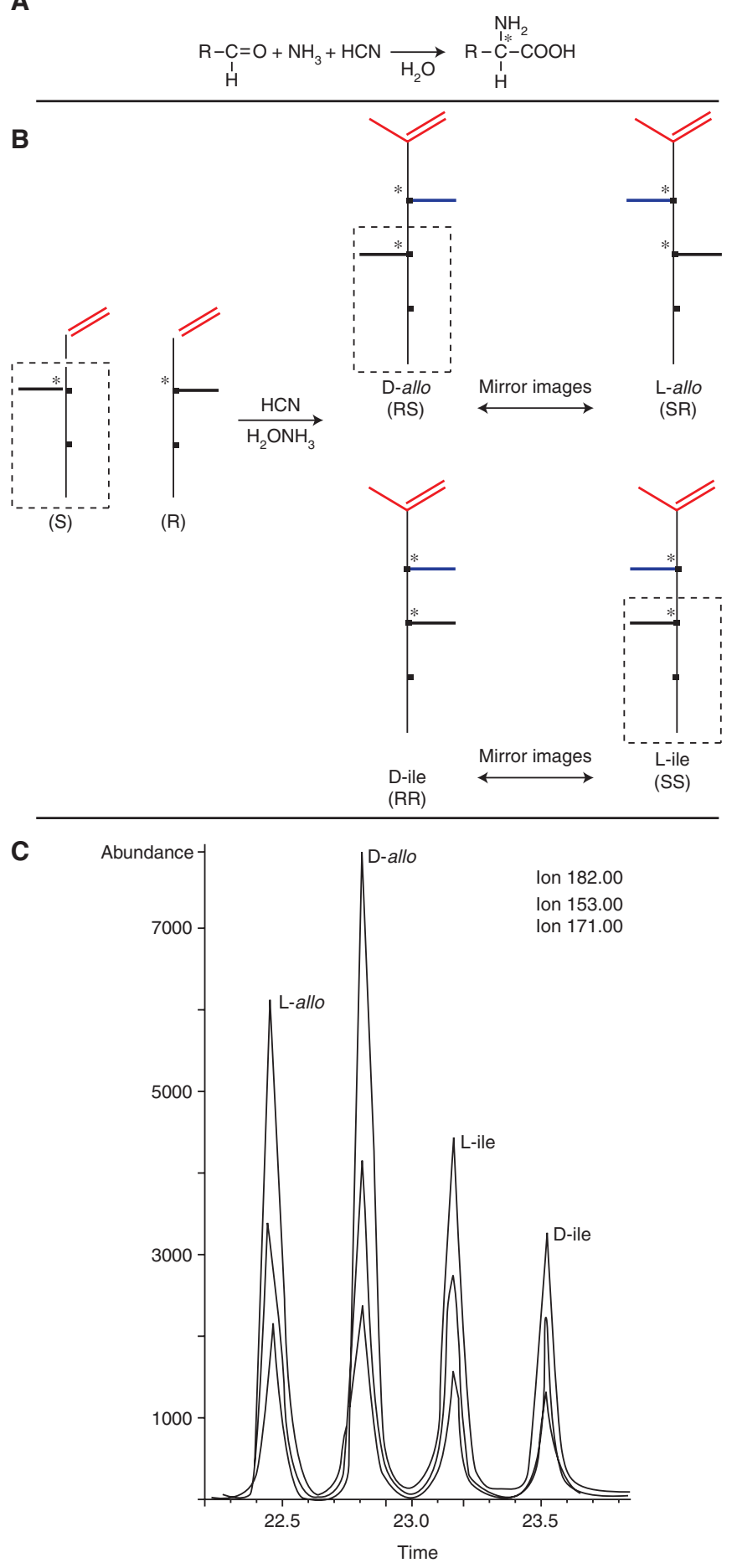

Figure 5. Possible formative pathway of the isoleucine (ile)-alloisoleucine (allo) diastereomers in meteorites. $(A)$ The cyanohydrine reaction. $(B)$ Schematic of the distribution of ile and allo following the same reaction with a 2-methylbutyraldehyde precursor. $(C)$ A chromatogram of the ile-allo diatereomers in the GRA 95229 meteorite. 
nonstereospecific because the HCN addition would be random and give equal amounts of D- and L-enantiomers. However, the reaction results become more complex for longer aldehydes that already contain an asymmetric carbon, for example, in the synthesis of the four ile and allo diastereomers from DL 2-methyl butanal. In this case, were an ee present in the aldehyde, e.g., of the (S) configuration, those amino acids that carried the S-portion of the molecule through their synthesis (shown between dotted squares in Fig. 2B) will be more abundant than their respective enantiomers. In the above example, this would be the (RS) allo and (SS) ile compounds or, in the formalism used for amino acids, D-allo and L-ile. Such was the distribution of isoleucine diastereomers found in the CR2 extracts (Fig. 5C) that, on the basis of the above formative premise, was interpreted to signify that their precursor aldehyde enantiomers carried an original S-bias to the meteorite's parent body.

Overall, the compositional differences between CR2- and Murchison-type meteorites make stark contrasts. Where the heterogeneity of Murchison compounds easily points to the difficulties that a primordial "soup" would encounter in molecular evolution, CR2 organic distributions and abundances have the unquestionable prebiotic appeal of being over abundantly water-soluble, N-containing, and of low molecular weight. Regardless of how CR2 organic material came to be, it is also clear that an unknown combination of elemental composition, energetic availabilities, and cosmic contingencies made CR2 precursor environments capable of a de facto selectivity of such "prebiotically desirable" molecular species.

Whether CR2 meteorite parent bodies would fit the new category (Levison et al. 2009) of "trans-Neptunian" objects or not, certainly the formative environments and histories of their organic materials must have differed from those of CMs. That the known ee-carrying amino acids as well as their ee are in lower abundance in CR2 than CM meteorites, whereas ee appear larger in a precursor aldehydes, would seem to further allow the general inference that abiotic organic pools in chemical evolution were diverse and differed in both their composition and exposure to asymmetric effects.

\section{The Long Cosmic History of Meteorites' Organic Materials}

The formation of meteoritic organic compounds was actively debated after Murchison's fall and the revelation that a large variety of extraterrestrial organic molecules with counterparts in the biosphere could be made abiotically. Clearly, to know the syntheses and locals responsible for their formation may have profound significance for the origin of extant life and even a broader exobiology. The earlier hypotheses all focused on solar system processes and, of these, the more influential were the suggestion of possible Miller-Urey type (Miller et al. 1976) syntheses in small planets, following production and recombination of radicals, and of catalytic, FisherTropsch-type, processes in the early stages of the solar nebula, where carbon monoxide could have undergone hydrogenation to hydrocarbons and other compounds (Lancet and Anders 1970). Eventually, the history of the organic compounds in carbonaceous meteorites was elucidated, at least in general terms, by the stable isotope analyses of several compounds and compound classes in the Murchison meteorite.

The isotopic composition is a good indicator of any molecule's synthetic history because the mass differences between isotopomers result in energy differences in their bond formation and may lead to a mass dependent fractionation, which becomes diagnostic of the physicochemical conditions affecting those reactions. Ultimately, isotopic fractionation is a function of zero point energy difference between isotopomers $(\Delta \mathrm{E})$ and local temperature, in the form: $\exp (-\Delta \mathrm{E} / \mathrm{T})$. In other words, the larger the energy difference between isotope bonds and the lower the temperature, the greater the potential for heavy isotope enrichment. Between the biogenic elements, therefore, hydrogen has the potential for the most enrichment in ${ }^{2} \mathrm{H}$ (deuterium, D) at low $\mathrm{T}$, because of the high relative mass difference of $\mathrm{D} / \mathrm{H}$ isotope pair $(2 / 1 \mathrm{u}$, e.g., compared to $\left.{ }^{13} \mathrm{C} /{ }^{12} \mathrm{C}=1.084\right)$. The most 
dramatic demonstration of these capabilities is given by the spectroscopic observations of the $\mathrm{D} / \mathrm{H}$ ratios of molecules formed in the dense clouds of the interstellar medium where temperatures are in the $10-30 \mathrm{~K}$ range. Over a hundred such molecules have been described (e.g., Roueff and Gerin 2002), many of which show extremely high $\mathrm{D} / \mathrm{H}$ ratios. For example, the average $\mathrm{D} / \mathrm{H}$ ratio in terrestrial organic compounds is approximately $1.5 \times 10^{-4}$, whereas a $\mathrm{D} / \mathrm{H}$ ratio as high as 0.33 has been observed in the interstellar molecule $\mathrm{D}_{2} \mathrm{CO} / \mathrm{DHCO}$ (Loinard et al. 2000).

Most Murchison compounds were found enriched in $\mathrm{D}$ and ${ }^{13} \mathrm{C}$ to varying degrees and these data, which alone suggest a relation between such molecules or their direct precursors and cold synthetic environments, led to a general theory of formation of meteorite organics that involved interstellar as well as parent body processes. By this hypothesis, icy asteroidal bodies accreted with abundant volatiles, including water and deuterium-rich interstellar organics that, upon warming and a subsequent period of aqueous phase chemistry, yielded the various soluble organic compounds of meteorites.

The possibility of parent body aqueous syntheses seems confirmed by the likelihood that at least some of Murchison amino acids were formed via a Strecker-like reaction of precursor aldehydes and ketones, ammonia and $\mathrm{HCN}$ (Fig. 5A). The evidence supporting this hypothesis is the finding in the Murchison meteorite of comparable suites of $\alpha$-amino and $\alpha$-hydroxy linear acids (although this correspondence is not valid for the $\alpha$-methyl compounds) and of imino acids (e.g., Pizzarello and Cooper 2001). These are compounds in which two carboxyl-containing alkyl chains are bonded at the same amino group and would likely result from a Strecker synthesis, e.g., when an amino acid product becomes the reactant in place of ammonia (Fig. 5).

However, there are isotopic as well as molecular trends within the Murchison organic suite that reveal significant formative distinctions between individual compounds and cannot be accounted for by any simplified model. For example, not all of Murchison amino acids fall in the same range of deuterium enrichment, and asymmetry-carrying 2-methyl amino acids display far larger $\delta \mathrm{D}$ values than the $2-\mathrm{H}$ isomers (Fig. 6). Because a similar branched versus linear difference in $\mathrm{D}$-enrichment was also observed between 3- and 4-amino isomers, it seems reasonable to assume that branched molecular species were processed in cold environments to a different degree than the linear ones. On the other hand, 2-, 3- and 4-amino acids also show different trends of ${ }^{13} \mathrm{C}$ abundance with increasing chain lengths, which decreases in the case of the 2-amino acids while remains level, or even slightly increases, in the case of the others. That is, within each level of D-enrichment, various processes of chain elongation seem to have been possible. The obvious conclusion from these Murchison detailed analyses is that diverse cosmic regimes and synthetic processes might have participated in producing the organic composition of this type of meteorites.

The isotopic analyses of CR meteorites added to the above scenario. The $\delta \mathrm{D}$ differences between 2-amino acid types are still present and further magnified, with the two GRA95229 2-methyl amino acids analyzed showing the highest $\delta \mathrm{D}$ values $(+7200 \%$ o $)$ ever measured for an extraterrestrial molecule by direct analyses. However, $\delta^{15} \mathrm{~N}$ values determined for CR2 amino acids have a distribution between molecular subgroups that is opposite to the one of their $\delta \mathrm{D}$ values, with $2-\mathrm{H}$ amino acids having higher $\delta^{15} \mathrm{~N}$ than 2-methyl amino acids (Pizzarello and Holmes 2008).

Because of the near absence of molecular ${ }^{15} \mathrm{~N}$ values for cosmic environments ${ }^{3}$, only theoretical considerations can be offered for the CR2 findings. The ones offered by Charnley and Rodgers (2002, 2004, 2008) describe a mechanism for higher nitrogen fractionations in regions of the ISM, where the enhanced density and pressure that precede star formation would cause the freeze-out of most carbon- and

\footnotetext{
${ }^{3}$ The possibility of different stellar nucleosynthetic pathways for the element of nitrogen (e.g., Wannier et al. 1981) would also further complicate their interpretation.
} 
The Organic Composition of Carbonaceous Meteorites

A

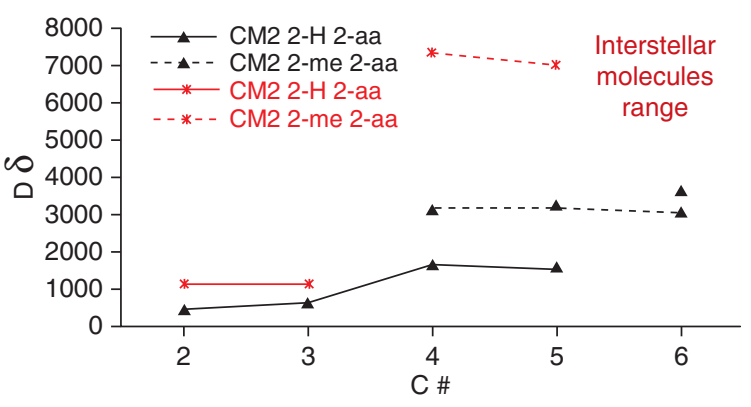

B

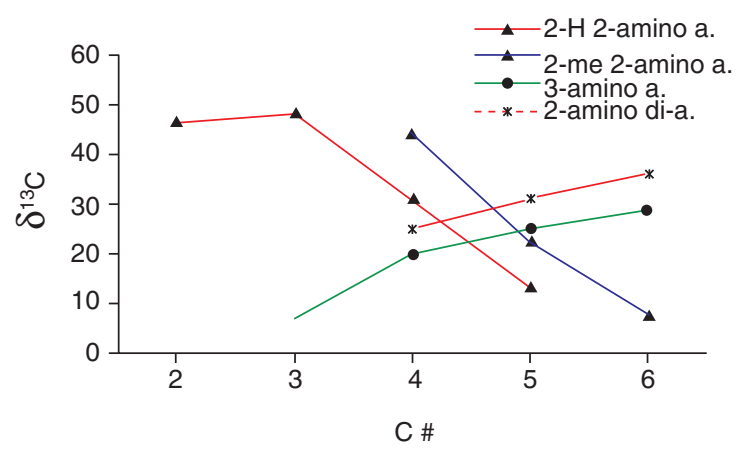

Figure 6. The hydrogen $(A)$ and carbon $(B)$ isotopic distributions of Murchison and CR2 amino acids.

oxygen containing molecules; with their disappearance, the disruption of $\mathrm{N}_{2}$ formation pathways in clouds of lesser density would result in a prevalence of gas-phase atomic nitrogen. In turn, this would lead to the efficient production of ammonia and ${ }^{15} \mathrm{NH}_{3} /{ }^{14} \mathrm{NH}_{3}$ ratios higher than the cosmic ${ }^{15} \mathrm{~N} /{ }^{14} \mathrm{~N}$ ratios (to as much as by $80 \%$ ).

These predictions are interesting in that they appear to match, albeit in broad terms, the findings in meteorites and the current interpretation of meteoritic amino acid formation. In fact, if the distinctly higher $\delta \mathrm{D}$ values of 2-methyl amino acids seem to point to their syntheses in cold ISM environments and the lower values of $2-\mathrm{H}$ amino acids to suggest that their syntheses took place at a later stage in the presence of liquid water, their $\delta^{15} \mathrm{~N}$ opposite trends would also fit with earlier (ISM) and later (prestellar cores) cosmochemical processes, albeit removed from a parent body environment.
Very little is known of the molecular sequence of events that would have taken place in a prestellar core; however, we can expect that several stages of temperature, pressure, and ensuing chemical regimes followed the initial collapse of the presolar portion of the ISM (e.g., Ceccarelli et al. 2007). We could hypothesize, therefore, that some of the warmer stages of star formation might have allowed selected environments, where the desorption, mixing, and reactions of radical, precursor molecules, water, and ammonia led to the syntheses of higher ${ }^{15} \mathrm{~N}$ amino acids and favored shorter molecular species formation. It also appears that such locals and the kinetic processes they allow to envision could, rather than parent body reactions, explain some of the molecular distributions seen in the CR meteorites, such as: the far from unity diastereomer ratios seen for the thermodynamically similar amino acids alloile and ile (Chaban and Pizzarello 2007), their erratic levels of enantiomeric excesses as 
well as the preponderance of lower chain length species and the abundance of unreacted carbonyl containing molecules (Pizzarello and Holmes 2009).

\section{Abiotic Pathways to Biomolecules}

Meteorites probably present just a minuscule sample of the prebiotic potential of cosmic synthetic processes but, through their studies, we may be able to infer how common or widespread they may be. Transformations of organic compounds, or their synthesis from inorganic compounds, occurs in response to thermodynamic drives, modulated by the kinetic properties of individual reactions. Setting aside the mechanistic details for a moment, it is useful to examine how reactions may or may not be favored by the thermodynamic properties of the system. Reactions involving organic compounds and occurring in aqueous solution may have occurred on meteorite parent bodies, smaller icy aggregates on their way to form asteroids or comets, and in selected prestellar environments; therefore, investigating relative stabilities of aqueous organic compounds may yield clues to these processes. This approach can help to answer specific questions about relative abundances of organic compounds found in carbonaceous meteorites. The following discussion illustrates this approach, with the specific goal of understanding the relative abundances of ammonia, amino acids, and aldehydes.

Stabilities of amino acids relative to other organic compounds during aqueous alteration can be assessed by considering a set of hypothetical overall reactions involving amino acids and other aqueous organic compounds. As an example, the stability of alanine relative to the aldehyde propanal can be assessed by considering a reaction in which carbon is conserved in the two aqueous organic compounds, given by

$$
\begin{aligned}
& \mathrm{CH}_{3} \mathrm{CH}_{2} \mathrm{CHO}(\mathrm{aq})+\mathrm{H}_{2} \mathrm{O}+\mathrm{NH}_{3}(\mathrm{aq}) \\
& \text { propanal } \\
& \quad=\mathrm{CH}_{3} \mathrm{CHNH}_{2} \mathrm{COOH}(\mathrm{aq})+2 \mathrm{H}_{2}(\mathrm{aq}), \\
& \quad \text { alanine }
\end{aligned}
$$

where the $(\mathrm{aq})$ indicates that the compounds of interest are all dissolved in $\mathrm{H}_{2} \mathrm{O}$. This reaction is not meant to depict a specific synthetic process, but instead delineates relative stabilities. It is evident from reaction (1) that there could be abundances of $\mathrm{NH}_{3}(\mathrm{aq})$ that would favor the stability of alanine relative to propanal. Likewise, at strongly reduced conditions, where there may be considerable $\mathrm{H}_{2}(\mathrm{aq})$ present, alanine would become unstable relative to propanal and $\mathrm{NH}_{3}(\mathrm{aq})$. Quantifying the activities (and concentrations) of $\mathrm{NH}_{3}(\mathrm{aq})$ and $\mathrm{H}_{2}(\mathrm{aq})$, where such transformations become possible, can be accomplished by considering the equilibrium constant for reaction (1), and manipulating its law of mass action expression. That expression, in its logarithmic form, is given by

$$
\begin{aligned}
\log \mathrm{K}= & \log \mathrm{aCH}_{3} \mathrm{CHNH}_{2} \mathrm{COOH}(\mathrm{aq}) \\
& +2 \log \mathrm{aH}_{2}(\mathrm{aq}) \\
& -\log \mathrm{aCH}_{3} \mathrm{CH}_{2} \mathrm{CHO}(\mathrm{aq}) \\
& -\log \mathrm{aNH}_{3}(\mathrm{aq})-\log \mathrm{aH}_{2} \mathrm{O} .
\end{aligned}
$$

In most dilute aqueous solutions (salinity $<$ seawater, as a rule of thumb), it can be safely assumed that the activity of $\mathrm{H}_{2} \mathrm{O}$ is so close to 1 that setting it equal to 1 introduces only trivial uncertainty. With this assumption, Equation (2) can be rearranged to give

$$
\begin{gathered}
\log \mathrm{aNH}_{3}(\mathrm{aq})=2 \log \mathrm{aH}_{2}(\mathrm{aq})-\log \mathrm{K} \\
+\log \left(\frac{\mathrm{aCH}_{3} \mathrm{CH}_{2} \mathrm{CHO}(\mathrm{aq})}{\mathrm{aCH}_{3} \mathrm{CHNH}_{2} \mathrm{COOH}(\mathrm{aq})}\right)
\end{gathered}
$$

which represents the equation of a line on a plot of $\log \mathrm{aNH}_{3}(\mathrm{aq})$ vs $\log \mathrm{aH}_{2}(\mathrm{aq})$ with a slope of 2 and an intercept equal to

$$
-\log \mathrm{K}+\log \left(\frac{\mathrm{aCH}_{3} \mathrm{CH}_{2} \mathrm{CHO}(\mathrm{aq})}{\mathrm{aCH}_{3} \mathrm{CHNH}_{2} \mathrm{COOH}(\mathrm{aq})}\right) .
$$

At constant temperature and pressure, $\log \mathrm{K}$ is a constant, which means that various lines can be determined based on the activity ratio of alanine to propanal. 
The Organic Composition of Carbonaceous Meteorites
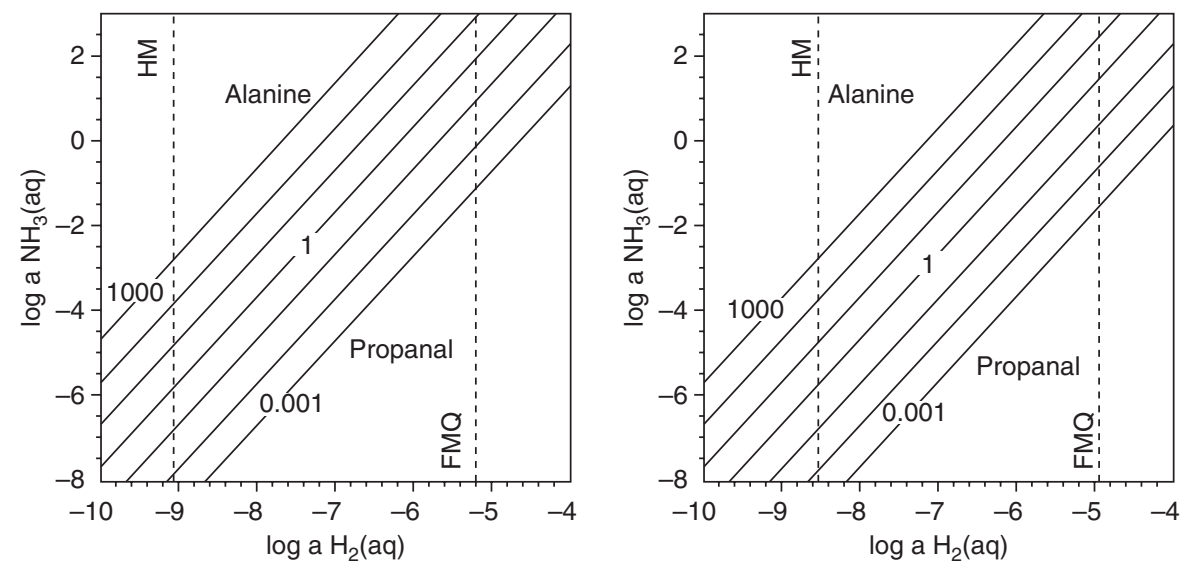

Figure 7. Equilibrium activity diagrams showing the relative stabilities of aqueous alanine and propanal in terms of the activities of $\mathrm{NH}_{3}(\mathrm{aq})$ and $\mathrm{H}_{2}(\mathrm{aq})$ at (left) $0^{\circ} \mathrm{C}$ and 1 bar and (right) $25^{\circ} \mathrm{C}$ and 1 bar. Selected contours of the equilibrium ratio of activities of alanine to propanal from 1000 to 0.001 are indicated. Equilibrium constants for reaction (1) were calculated with the revised Helgeson-Kirkham-Flowers equation of state (Shock et al. 1992) using data and parameters from Shock et al. (1989); Shock and Helgeson (1990) and Shulte and Shock (1993). Also shown are activities of $\mathrm{H}_{2}(\mathrm{aq})$ corresponding to equilibrium between hematite and magnetite (HM, reaction 4), as well as magnetite, quartz, and fayalite (FMQ, reaction 5). Thermodynamic data for minerals come from Helgeson et al. (1978). All calculations were conducted with the software package SUPCRT92 (Johnson et al. 1992).

Plots of this type are shown in Figure 7 for $0^{\circ} \mathrm{C}$ and $25^{\circ} \mathrm{C}$ both at 1 bar, with contours of the activity ratio ranging from 0.001 to 1000 . The bold contour labeled 1 in each plot shows the position of equal activities of the two organic solutes at equilibrium. Ranges of relative predominance of propanal and alanine are indicated, with that of alanine in each plot falling at higher activities of $\mathrm{NH}_{3}(\mathrm{aq})$ and lower activities of $\mathrm{H}_{2}(\mathrm{aq})$, consistent with Le Chatlier's principle applied to reaction (1). Also shown in these diagrams are the values of log a $\mathrm{H}_{2}(\mathrm{aq})$, at which hematite $\left(\mathrm{Fe}_{2} \mathrm{O}_{3}\right)$ would be reduced to magnetite $\left(\mathrm{Fe}_{3} \mathrm{O}_{4}\right)$, consistent with

$$
3 \mathrm{Fe}_{2} \mathrm{O}_{3}+\mathrm{H}_{2}(\mathrm{aq})=2 \mathrm{Fe}_{3} \mathrm{O}_{4}+\mathrm{H}_{2} \mathrm{O},
$$

and where magnetite would be reduced to the ferrous silicate fayalite $\left(\mathrm{Fe}_{2} \mathrm{SiO}_{4}\right)$ in the presence of quartz $\left(\mathrm{SiO}_{2}\right)$ according to

$$
\begin{gathered}
\mathrm{Fe}_{3} \mathrm{O}_{4}+\mathrm{H}_{2}(\mathrm{aq})+3 / 2 \mathrm{SiO}_{2} \\
=3 / 2 \mathrm{Fe}_{2} \mathrm{SiO}_{4}+\mathrm{H}_{2} \mathrm{O} .
\end{gathered}
$$

Magnetite, which is one of the aqueous alteration products identified in $\mathrm{CI}, \mathrm{CM}, \mathrm{CO}, \mathrm{CR}$, CV meteorites and some LL3 chondrites (Zolensky et al. 2008) would be stable between the two vertical dashed lines on each plot.

The presence of magnetite brackets the equilibrium activities of $\mathrm{H}_{2}(\mathrm{aq})$ that could have attained during at least a portion of the aqueous alteration processes occurring on the Murchison parent body. If this alteration occurred at $0^{\circ} \mathrm{C}$, then the equilibrium activity of $\mathrm{H}_{2}$ (aq) fell between about $10^{-5.2}$ and $10^{-9.1}$. If, on the other hand, temperatures were warmer, these activities would change. As an example, at $25^{\circ} \mathrm{C}$, the equilibrium activities of $\mathrm{H}_{2}$ (aq) fall between $10^{-4.9}$ and $10^{-8.5}$. In dilute solutions, activities of neutral solutes correspond closely to concentrations (Amend and Shock 2001).

These plots reveal the ranges of $\mathrm{H}_{2}(\mathrm{aq})$ concentrations that are consistent with the occurrence of magnetite, and the $\mathrm{NH}_{3}(\mathrm{aq})$ concentrations that would provide a thermodynamic drive for the formation of an amino acid rather than an aldehyde, and vice versa. 
At, for example, log a $\mathrm{H}_{2}(\mathrm{aq})=-7$ (equal to about 100 nanomolar dissolved $\mathrm{H}_{2}$ ), conditions in the middle of the range of magnetite stability, activities of $\mathrm{NH}_{3}(\mathrm{aq})>10^{-2}$ at $0^{\circ} \mathrm{C}$, and $>10^{-3}$ at $25^{\circ} \mathrm{C}$, would favor the formation of alanine at abundances greater than those of propanal. Whether or not equilibrium is actually attained among organic compounds during aqueous alteration events on meteorite parent bodies, the persistent thermodynamic drive to form amino acids or aldehydes depends on the chemical composition of the system. The plots in Figure 7 reveal the quantitative nature of those thermodynamic drives. They also make it possible to begin to understand the amounts of $\mathrm{NH}_{3}$ (aq) that would be required if amino acid concentrations were similar to aldehyde concentrations or vastly different.

Comparison of the data from the CR2 meteorites and Murchison shown in Figure 4 indicates that the ratio of total amino acids to aldehydes+ketones is on the order of 12 for LAP and about two for GRA and Murchison. It can also be seen that ammonia abundances are greatest in GRA, similarly large in LAP, and very low in Murchison. These data can be combined with the thermodynamic analysis depicted in Figure 7 in an attempt to evaluate what conditions were like during aqueous alteration, if the relative abundances of aldehydes and amino acids were influenced by that stage of meteorite history. It should be kept in mind that the data that exist are for what is present in the meteorites and not what may have been present in aqueous solution during the alteration process. Adsorption equilibria among solutions and various mineral phases may differ for these two classes of organic compounds, and much could have happened to alter ratios inherited from such an early stage in the history of the solar system. Let us assume that the relative abundances of organic compounds in meteorite extracts reflects conditions on the parent bodies at the time the compounds formed and that they were not radically reset by subsequent history.

Starting with LAP, conditions consistent with the overall amino acid to aldehyde ratio would fall just above and to the left of the 10 contour, which is the first above the equal activity $(=1)$ contour in a plot like those shown in Figure 7 for the presently unknown temperature of aqueous alteration. If the amino acid to aldehyde ratio is a result of aqueous alteration, then it provides us with this locus of possibilities in $\log \mathrm{a} \mathrm{NH}_{3}$ (aq) versus $\log$ a $\mathrm{H}_{2}$ (aq) space. Likewise, ratios from GRA and Murchison indicate that conditions during aqueous alteration may have generated conditions near or slightly above the equal activity contour. If there were estimates of the activity of either $\mathrm{H}_{2}(\mathrm{aq})$ or $\mathrm{NH}_{3}(\mathrm{aq})$ that prevailed during aqueous alteration, then the equilibrium value of the other would be uniquely defined by the ratio of organic compounds.

Assuming that the relative abundances of ammonia in the extracts are analogous to the relative abundances during aqueous alteration leads to the following assessment of relative oxidation-reduction (redox) states during aqueous alteration events. The amino acid to aldehyde ratios in GRA and Murchison are about equal, but the abundance of ammonia that can be extracted from GRA is much greater. Therefore, it seems likely that conditions during aqueous alteration of the Murchison parent body would plot at a lower activity of $\mathrm{NH}_{3}(\mathrm{aq})$ than those that attained during alteration of the GRA parent body. If so, then the fact that both meteorites fall on about the same contour means that the activity of $\mathrm{H}_{2}(\mathrm{aq})$ was much greater during alteration of GRA than during alteration of Murchison if alteration processes happened at similar temperatures on both parent bodies. The abundance of ammonia in the LAP extracts is nearly as great as the GRA extracts, but the amino acid to aldehyde ratio is also greater. If the temperature of alteration of LAP was similar to that of GRA, then conditions during the alteration of LAP would fall somewhat lower in $\log \mathrm{a} \mathrm{NH}_{3}(\mathrm{aq})$, but also considerably lower in the activity of $\mathrm{H}_{2}(\mathrm{aq})$ to maintain the higher amino acid to aldehyde ratio. All else being equal, indications are that conditions were most oxidized during alteration of the Murchison parent body, most reduced during alteration of GRA, and intermediate during the alteration of LAP. Corroborating evidence may be found in the relative abundances of 
carboxylic acids, which are more oxidized than either amino acids or aldehydes. Redox conditions during alteration directly affect the potential for abiotic organic synthesis (Shock 1990; 1992a; Shock and Schulte 1990; 1998; Amend and Shock 1998; Shock and Canovas 2010). If the analysis outlined above survives deeper scrutiny, the overall potential for abiotic organic synthesis from inorganic starting compounds may have been greatest on the GRA parent body, despite its lower abundances of amino acids.

There are several ways that these predictions of relative redox states can be tested. One would be to examine the mineralogy of the alteration products in all three meteorites for evidence of mineral assemblages that could indicate redox conditions that prevailed during alteration. Another would be to seek evidence from mineral assemblages, organic compound associations, and isotopes (oxygen in pairs or suites of minerals that formed together, for example) that could bracket the temperatures of the alteration events on each parent body so that quantitatively appropriate versions of the plots in Figure 7 could be built. Also, experimental studies of the adsorption of ammonia, amino acids, aldehydes, and other organic compounds commonly extracted from meteorites on minerals found in meteorite alteration assemblages would enable estimation of aqueous concentrations or activities from the abundances of these compounds in the meteorites.

\section{Exogenous Delivery and Molecular Evolution}

\section{The Monomers and Their Potential}

If we trust the record of impact craters observed in most of solar planets and satellites, meteorites have showered the Earth throughout geological ages and certainly did so soon after its accretion (e.g., Chyba and Sagan 1992). Abundant organic materials were just as certainly delivered to the early Earth and, it is reasonable to assume, a good portion of them survived the process. We have learned from the analyses of two largely different types of meteorites that this exogenous input delivered both complex macromolecules of uncertain composition and free soluble compounds. Various molecular species must have interacted in the meteorites already prior to their fall, to a certain degree, because some derivative compounds such as the carboxamides (Cooper and Cronin 1995) are released from their extracts upon hydrolysis; however, peptides have been carefully searched for in the Murchison meteorite and not found, with the exception of diglycine (Shimoyama and Ogasawara 2002). If we are trying to estimate the potential of this delivery for prebiotic evolution and we believe that such evolution had to gain some polymeric complexity for life to ensue, then, we have to conclude that the bulk of meteoritic compounds could have provided, at best, monomeric constituents. In general, however, any evolutionary path has to rely on monomeric material as well and, just comparing with other early planetary processes that could have led to organic compounds such as atmosphere-mediated Miller-Urey-type syntheses or the environment of hydrothermal vents, the molecular species ready-made in meteorites would not appear as too bad of a start. Of these, meteoritic amino acids appear as likely candidates for further molecular evolution, particularly considering their selective and abundant suites found in CR2 chondrites.

Amino acids, the components of extant proteins, are able to polymerize under a variety of laboratory conditions and could have done so in early Earth environments. For example, Oro' and Guidry (1961) first showed that glycine readily polymerizes in the presence of ammonia and little water at temperatures of about $140^{\circ} \mathrm{C}$. Also Leman, Orgel, and Ghadiri (2004) showed that the presence of carbonyl sulfide, such as it is found around volcanoes, could lead to easy formation of peptides. When of the type found nonracemic in Murchison, amino acids readily form an activated carboxyl, e.g., as an oxazolone by intramolecular dehydration, and polymerize conforming into helixes at lengths as short as three-amino acid units (Crisma et al. 2004).

These findings suggest that it is plausible that exogenous amino acids acquired at least some polymeric complexity during early terrestrial evolution; it is as likely that their overall molecular properties might have been 
evolutionary factors as well. For example, all ee found so far for meteoritic amino acids have just one configuration, L-, whereas those obtained for chiral molecules in natural processes, designed experiments, or via theoretical schemes are all subjected to chance outcome in the absence of asymmetric influences. Similarly, several terrestrial crystals such as quartz are chiral but their world-wide production is about equal in $d$ - and $l$-forms. Also, so far, ee have been found in amino acids that do not racemize ${ }^{4}$, meaning that their ee could have been preserved in prebiotic aqueous environments.

Most importantly, amino acids as well as peptides are molecules with diverse catalytic properties that are readily displayed experimentally and in biochemistry. They can also be asymmetric catalysts, a fact suggesting that the unique molecular asymmetry of meteoritic amino acids might have been a particularly useful evolutionary tool. A set of experiments have been conducted with this theme, to assess the possibility that the nonracemic amino acids of meteorites could have acted as catalysts during early Earth molecular evolution and transferred their asymmetry to other prebiotic building blocks such as sugars. It was found that both amino acids and dipeptides can catalyze the asymmetric aldol condensation of glycolaldehyde, or glycolaldehyde and glyceraldehyde, to produce tetrose (Pizzarello and Weber 2004; Weber and Pizzarello 2006) and pentose (Pizzarello and Weber 2010) sugars with significant $e e$. It is interesting that these syntheses singled out D-erythrose and D-ribose in forming ee with LL dipeptides catalysts, whereas all other sugars acquired either $e e$ of the same configuration as the catalyst or, in some cases, no ee at all. These reactions were conducted in buffered water solution, made use of simple reactant realistically available to the early Earth, and implied likely catalytic pathways under mild

${ }^{4}$ Racemization, the reversal of configurations in water, involves the loss and reacquisition of hydrogen by the carbon adjacent to the carboxyl group, which is slightly acidic, and is not allowed when the $\mathrm{H}$ at $\mathrm{C}-2$ is substituted with a methyl group. conditions. They have, therefore, some prebiotic credibility and support the conclusion that, whereas the extent to which meteoritic catalysts might have been effective in a mixture is entirely unknown, their possible inductive effect toward chiral asymmetry in the monomeric interactions of molecular evolution cannot be disregarded.

\section{Energetic Contingencies}

Knowing that life ensued rather quickly in early Earth history, it seems also realistic to assume that the planet environments might have been part of the unknown contingencies that fostered the transition from abiotic chemistry to the molecular evolution that preceded the emergence of life. If so, these environments would have combined available organic compounds with favorable catalysts, which might have been organic as well as inorganic. Just as all known life forms have habitats, the emergence of life may have had a habitat as well (Shock et al. 1998, 2000).

Because the record of Earth's first geological era was lost to ensuing diagenetic and metamorphic changes, clays represent the first alteration products of basaltic glass under hydrous conditions and would be good candidates for aiding simple abiotic molecules, such as those found in meteorites, in undertaking evolutionary steps of prebiotic significance. As detailed in Deamer and Weber (2010), these minerals are known to adsorb organic molecules and actively participate as catalysts in their syntheses and reactions (Williams et al. 2005). In particular, the smectite group of expandable clays, such as montmorillonite and saponite, can undergo surface energy changes during diagenesis that will affect their surface $\mathrm{H}$-bonding at key sites and form complex aromatic and polyaromatic hydrocarbons of up to $\mathrm{C}_{20}$ from methanol (e.g., Williams et al. 2005).

Also, as mentioned above, conditions of very low $\mathrm{H}_{2} \mathrm{O}$ activities or elevated temperatures in aqueous solution can drive polymerization reactions that involve dehydration such as peptide formation. The latter possibility has inspired several experimental investigations of the 
potential for amino acid polymerization under hydrothermal conditions (Shock 1992b, 1993). Starting with amino acids, it has repeatedly been shown that dipeptides and cyclic dipeptides form rapidly in hydrothermal experiments (Imai et al. 1999b; Alargov et al. 2002; Li and Brill 2003; Lemke et al. 2009; Cleaves et al. 2009). Occasionally, these experimental studies also obtain small concentrations of tripeptides and longer oligomers (Imai et al. 1999a; Tsukahara et al. 2002), but the formation of cyclic dipeptides, which is thermodynamically favored (Shock 1992b), often dominates. It has also been shown that if experiments are started with somewhat larger oligomers, say three or four amino acids in length, then the peptides can be lengthened by hydrothermal reactions involving the monomers (Kawamura et al. 2005), and that polymers containing up to 20 amino acids can be generated hydrothermally from glutamic acid or aspartic acid, which do not form cyclic dipeptides (Kawamura and Shimahashi 2008). In addition, hydrothermal dehydration reactions involving alkanoic acids and glycerol produce lipid-like molecules capable of self-assembly (Simoneit et al. 2007). Taken together, these recent results show that condensation, polymerization, and peptide bond formation may commonly occur in hydrothermal conditions. If so, planetary processing of materials supplied from meteorites may have been integral to the emergence of living systems.

\section{CHALLENGES AND FUTURE RESEARCH DIRECTIONS}

Carbonaceous chondrites are natural samples of limited and unpredicted availability that, once reaching the Earth, are under the constant threat of terrestrial contamination. Their study has obviously met with challenges of material preservation, designing of analytical methodologies, identification of indigenous materials, and more; these will remain, mutatis mutandis, much the same in the future. Nonetheless, these meteorites have been analyzed successfully in great detail and their studies have been invaluable in determining the prebiotic possibilities of cosmochemical environments; however, they have not answered the basic exobiological question of whether extraterrestrial organic compounds contributed to molecular evolution on the early Earth and to the emergence of life.

That answer may never be possible, but, if we believe with Eschenmoser (2008) that life's origin " . . cannot be discovered, as other things in science, it can only be re-invented", meteorite analyses will offer realistic molecular tools to attempt just that and much still can be done. After forty years of studying Murchison-type meteorites, a new group of Antarctic finds has shown that within the diverse cosmic environments may reside the capabilities of forming organic suites enriched in biomolecule precursors and of high prebiotic appeal. The CR2 organic compounds are still poorly characterized but new studies will define their extent and distribution. Many small molecules that could be useful for initiating molecular evolution could have escaped detection in earlier studies of these pristine meteorites and have not yet been targeted for analyses: glycolaldehyde, glyceraldehydes (detected but not quantified or unpublished), HCN, formamide, urea, and small peptides are all "stuff" required for modeling early evolutionary biology. Hopefully, we shall know soon their distribution in space also.

\section{REFERENCES}

Alargov DK, Deguchi S, Tsujii K, Horikoshi K. 2002. Reaction behaviors of glycine under super- and subcritical water conditions. Origins Life Evol Biosph 32: 1-12.

Amend JP, Shock EL. 1998. Energetics of amino acid synthesis in hydrothermal ecosystems. Science 281: 1659-1662.

Amend JP, Shock EL. 2001. Energetics of overall metabolic reactions in thermophilic and hyperthermophilic Archaea and Bacteria. FEMS Microbiology Reviews 25: 175-243.

Arteaga O, Canillas A, Crusats J, El-Achemi Z, Jellison JE, Llorca J, Ribó JM. Chiral biases in solids by effect of sheer gradients: A speculation on the deterministic origin of biological homochirality. Orig Life Evol Biosph 40: $27-40$.

Ceccarelli C, Caselli P, Herbst E, Tielens AGGM, Caux E. 2007. Extreme deuteration and hot Corinos: The earliest chemical signatures of low-mass star formation. In Protostars and planets (ed. Reipurth VB, Jewitt D, Keil K), pp. 47-62. The University of Arizona Press, Tucson, AZ. 
S. Pizzarello and E. Shock

Chaban G, Pizzarello S. 2007. Meteoritic amino acids: The product of still unknown cosmic and solar environments. Abstracts of papers, 39th Lunar and Planetary Conference, Houston, TX. Abstract \# 1389.

Charnley SD, Rodgers SB. 2002. The end of interstellar chemistry and the origin of nitrogen in comets and meteorites. A J 569: L133-L137.

Chyba CF, Sagan C. 1992. Endogenous production, exogenous delivery, and impact-shock synthesis of organic molecules: an inventory for the origins of life. Nature 355: $125-132$

Cleaves HJ, Aubrey AD, Bada JL. 2009. An evaluation of the critical parameters for abiotic peptide synthesis in submarine hydrothermal systems. Origins of Life and the Evolution of the Biosphere 39: 109-126.

Cooper GW, Cronin JR. 1995. Linear and cyclic aliphatic carboxamides of the Murchison meteorite: Hydrolyzable derivatives of amino acids and other carboxylic acids. Geochim Cosmochim Acta 59: 1003-1015.

Crick FHC, Orgel LE. 1973. Directed panspermia. Icarus 19: 341-346.

Crisma M, Moretto A, Formaggio F, Kaptein B, Broxterman QB, Toniolo C. 2004. Meteoritic $C^{\alpha}$-methylated $\alpha$-amino acids an the homochirality of life: Searching for a link. Angew Chem Int Ed 43: 6695-6699.

Cronin JR, Pizzarello S. 1997. Enantiomeric excesses in meteoritic amino acids. Science 275: 951-955.

Deamer D. 1985. Boundary structures are formed by organic components of the Murchison carbonaceous chondrite. Nature 317: 792-794.

Deamer D, Weber AL. 2010. Bioenergetics and life's origins. Cold Spring Harb Perspect Biol 2: a004929.

Eschenmoser A. 2008. Fundamental questions: An interview with Albert Eschenmoser. In The Scripps Research Institute News and Views: 8. http://www.scripps.edu/ newsandviews/e_20080421/.

Helgeson HC, Delany JM, Nesbitt WH, Bird DK. 1978. Summary and critique of the thermodynamic properties of rock forming minerals. Am J Sci 278A: 1-229.

Imai E-I, Honda H, Hatori K, Brack A, Matsuno K. 1999a. Elongation of oligopeptides in a simulated submarine hydrothermal system. Science 283: 831-833.

Imai E-I, Honda H, Hatori K, Matsuno K. 1999b. Autocatalytic synthesis of oligoglycine in a simulated submarine hydrothermal system. Origins of Life and Evolution of the Biosphere 29: 249-259.

Johnson JW, Oelkers EH, Helgeson HC. 1992. SUPCRT92: A software package for calculating the standard molal thermodynamic properties of minerals, gases, aqueous species, and reactions from 1 to 5000 bar and 0 to $1000^{\circ} \mathrm{C}$. Computers \& Geosciences 18: 932-934.

Kawamura K, Shimahashi M. 2008. One-step formation of oligopeptide-like molecules from Glu and Asp in hydrothermal environments. Naturwissenschaften 95: 449454.

Kawamura K, Nishi T, Sakiyama T. 2005. Consecutive elongation of alanine oligopeptides at the second time range under hydrothermal conditions using a microflow reactor system. J Am Chem Soc 127: 522-523.

Kawasaki T, Hatase K, Fujii Y, Jo K, Soai K, Pizzarello S. 2006. The distribution of chiral asymmetry in meteorites: An investigation using asymmetric autocatalytic chiral sensors. Geochim Cosmochim Acta 70: 5395-5402.

Lazcano A. 2010. Historical development of origins research. Cold Spring Harb Perspect Biol 2: a002089.

Leman L, Orgel L, Ghadiri MR. 2004. Carbonyl sufidemediated prebiotic formation of peptides. Science 306: 283-286.

Lemke KH, Rosenbauer RJ, Bird DK. 2009. Peptide synthesis in early Earth hydrothermal systems. Astrobiology 9: 141-146.

Levison HF, Bottke WF, Gounelle M, Morbidelli A, Nesvorn D, Tsiganis K. 2009. Contamination of the asteroid belt by primordial trans-Neptunian objects. Nature 460: 364-366.

Li J, Brill TB. 2003. Spectroscopy of hydrothermal reactions. 27. Simultaneous determination of hydrolysis rate constants of glycylglycine to glycine and glycylglycinediketopiperazine equilibrium constants at $310-330^{\circ} \mathrm{C}$ and 275 bar. J Phys Chem A 107: 8575-8577.

Loinard S, Castets A, Ceccarelli C, Tielens AGGM, Faure A, Caux E, Duvert G. 2000. Double deuterated molecular species in protostellar environments. Astron Astrophys 359: $1169-1174$

Luisi PL. 2007. Presented at: International School of Complexity-4th course: Basic questions on the Origin of Life; Ettore Majorana Foundation and Centre for Scientific Culture, Erice, Italy, 1-6 October 2006.

Mautner MN, Leonard R, Deamer DW. 1995. Meteorite organics in planetary environments: Hydrothermal release, surface activity and microbial utilization. Planet Space Sci 43: 139-147.

Miller SL, Urey HC, Oró J. 1976. Origin of organic compounds on the primitive earth in meteorites. J Mol Evol 9: $59-72$.

Oro' J, Guidry CL. 1961. Direct synthesis of polypeptide I. Polycondensation of glycine in aqueous ammonia. Arch Biochem Biophys 93: 166-171.

Pearson VK, Kearsley AT, Sephton MA, Gilmour I. 2007. The labelling of meteoritic organic material using osmium tetroxide vapour impregnation. Planet Space Sci 55: 1310-1318.

Peltzer ET, Bada JL. 1978. $\alpha$-Hydroxycarboxylic acids in the Murchison meteorite. Nature 272: 443-444.

Pizzarello S. 2009. The chemistry that preceded life's origin: When is an evolutionary story an emergent story? Orig Life Evol Biosph (in press).

Pizzarello S, Cooper GW. 2001. Molecular and chiral analyses of some protein amino acid derivatives in the Murchison and Murray meteorites. Meteorit Planet Sci 36: 897-909.

Pizzarello S, Holmes W. 2009. Nitrogen-containing compounds in two CR2 meteorites: ${ }^{15} \mathrm{~N}$ composition, molecular distribution and precursor molecules. Geochim Cosmochim Acta 73: 2150-2162.

Pizzarello S, Huang Y. 2005. The deuterium enrichment of individual amino acids in carbonaceous meteorites: A case for the presolar distribution of biomolecules precursors. Geochim Cosmochim Acta 69: 599-605.

Pizzarello S, Weber AL. 2004. Prebiotic amino acids as asymmetric catalysts. Science 303: 1151. 
Pizzarello S, Weber AL. 2010. Stereoselective syntheses of pentose sugars under realistic prebiotic conditions. Orig Life Evol Biosph 40: 3-10.

Pizzarello S, Zolensky M, Turk KA. 2003. Non racemic isovaline in the Murchison meteorite: chiral distribution and mineral association. Geochim Cosmochim Acta 67: $1589-1595$.

Pizzarello S, Huang Y, Alexandre MR. 2008. Molecular asymmetry in extraterrestrial chemistry: Insights from a pristine meteorite. Proc Natl Acad Sci 105: 3700-3704.

Rodgers SB, Charnley SB. 2004. Interstellar diazenylium recombination and nitrogen isotopic fractionation. Mont Not R Astron Soc 352: 600-604.

Rodgers SB, Charnley SB. 2008. Nitrogen superfractionation in dense cloud cores. Mont Not R Astron Soc 569: L48L52.

Roueff E, Gerin M. 2003. Deuterium in molecules of the interstellar medium. Space Scie Rev 106: 61-72.

Shimoyama A, Ogasawara R. 2002. Dipeptides and diketopiperazines in the Yamato-791198 and Murchison carbonaceous chondrites. Orig Life Evol Biosph 32: 165-179.

Shock EL. 1990. Geochemical constraints on the origin of organic compounds in hydrothermal systems. Origins Life Evol Biosph 20: 331-367.

Shock EL. 1992a. Chemical environments in submarine hydrothermal systems. In: Marine hydrothermal systems and the origin of life, (ed. N Holm) a special issue of Origins Life Evol Biosph 22: 67-107.

Shock EL. 1992b. Stability of peptides in high temperature aqueous solutions. Geochim Cosmochim Acta 56: 34813491.

Shock EL. 1993. Hydrothermal dehydration of aqueous organic compounds. Geochim Cosmochim Acta 57: 3341 3349.

Shock EL, Canovas P. 2010. The potential for abiotic organic synthesis and biosynthesis at seafloor hydrothermal systems. Geofluids (in press).

Shock EL, Helgeson HC. 1990. Calculation of the thermodynamic and transport properties of aqueous species at high pressures and temperatures: Standard partial molal properties of organic species. Geochim Cosmochim Acta 54: 915-945.

Shock EL, Schulte MD. 1990. Amino acid synthesis in carbonaceous meteorites by aqueous alteration of polycyclic aromatic hydrocarbons. Nature 343: 728-731.
Shock EL, Schulte MD. 1998. Organic synthesis during fluid mixing in hydrothermal systems. J Geophys Res 103: 28513-28527.

Shock EL, Amend JP, Zolotov MYu. 2000. The early Earth vs. the origin of life. In The origin of the Earth and Moon (ed. R Canup, K Righter), pp. 527-543. University of Arizona Press.

Shock EL, Helgeson HC, Sverjensky DA. 1989 Calculation of the thermodynamic and transport properties of aqueous species at high pressures and temperatures: Standard partial molal properties of inorganic neutral species. Geochim Cosmochim Acta 53: 2157-2183.

Shock EL, McCollom T, Schulte MD. 1998 The emergence of metabolism from within hydrothermal systems. In Thermophiles: The keys to molecular evolution and the origin of life? (ed. Adams Wiegel), pp. 59-76. Taylor \& Francis, London, UK.

Shock EL, Oelkers EH, Johnson JW, Sverjensky DA, Helgeson HC. 1992. Calculation of the thermodynamic properties of aqueous species at high pressures and temperatures: Effective electrostatic radii, dissociation constants, and standard partial molal properties to $1000^{\circ} \mathrm{C}$ and $5 \mathrm{~kb}$. J Chem Soc, Faraday Trans 88: 803-826.

Shulte MD, Shock EL. 1993. Aldehydes in hydrothermal solutions: Standard partial molal thermodynamic properties and relative stabiirties at high-temperatures and pressures. Geochim Cosmochim Acta 57: 3835-3846.

Simoneit BRT, Rushdi AI, Deamer DW. 2007. Abiotic formation of acylglycerols under simulated hydrothermal conditions and self-assembly properties of such lipid products. Adv Space Res 40: 1649-1656.

Tsukahara K, Imai E-I, Honda H, Hatori K, Matsuno K. 2002. Prebiotic oligomerization on or inside lipid vesicles in hydrothermal environments. Origins Life Evol Biosph 32: $13-21$.

Wannier PG, Linke RA, Penzias AA. 1981. Observations of $\mathrm{N}-14 \mathrm{~N}-15$ in the galactic disk. Ap J 247: 522-529.

Weber AL, Pizzarello S. 2006. The peptide catalyzed stereospecific synthesis of tetroses: A possible model for prebiotic molecular evolution. Proc Natl Acad Sci 103: 12713-12717.

Yabuta H, Wiliams LB, Cody GD, Alexander CMO'D, Pizzarello S. 2007. The insoluble carbonaceous material of CM chondrites: A possible source of discrete organic compounds under hydrothermal conditions. Meteor Planet Sci 42: 37-48. 


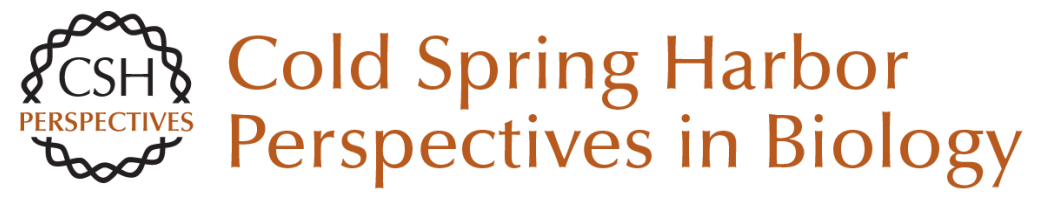

\section{The Organic Composition of Carbonaceous Meteorites: The Evolutionary Story Ahead of Biochemistry}

Sandra Pizzarello and Everett Shock

Cold Spring Harb Perspect Biol 2010; doi: 10.1101/cshperspect.a002105

\section{Subject Collection The Origins of Life}

Constructing Partial Models of Cells

Norikazu Ichihashi, Tomoaki Matsuura, Hiroshi Kita, et al.

Ribonucleotides John D. Sutherland

Deep Phylogeny--How a Tree Can Help

Characterize Early Life on Earth

Eric A. Gaucher, James T. Kratzer and Ryan N. Randall

Cosmic Carbon Chemistry: From the Interstellar

Medium to the Early Earth

Pascale Ehrenfreund and Jan Cami

Origin and Evolution of the Ribosome George E. Fox

Planetary Organic Chemistry and the Origins of Biomolecules Steven A. Benner, Hyo-Joong Kim, Myung-Jung Kim, et al.

Mineral Surfaces, Geochemical Complexities, and the Origins of Life

Robert M. Hazen and Dimitri A. Sverjensky

Historical Development of Origins Research Antonio Lazcano
The Hadean-Archaean Environment

Norman H. Sleep

An Origin of Life on Mars

Christopher P. McKay

Primitive Genetic Polymers

Aaron E. Engelhart and Nicholas V. Hud

Membrane Transport in Primitive Cells Sheref S. Mansy

The Origins of Cellular Life Jason P. Schrum, Ting F. Zhu and Jack W. Szostak

From Self-Assembled Vesicles to Protocells Irene A. Chen and Peter Walde

The Origin of Biological Homochirality Donna G. Blackmond

Earth's Earliest Atmospheres

Kevin Zahnle, Laura Schaefer and Bruce Fegley

For additional articles in this collection, see http://cshperspectives.cshlp.org/cgi/collection/

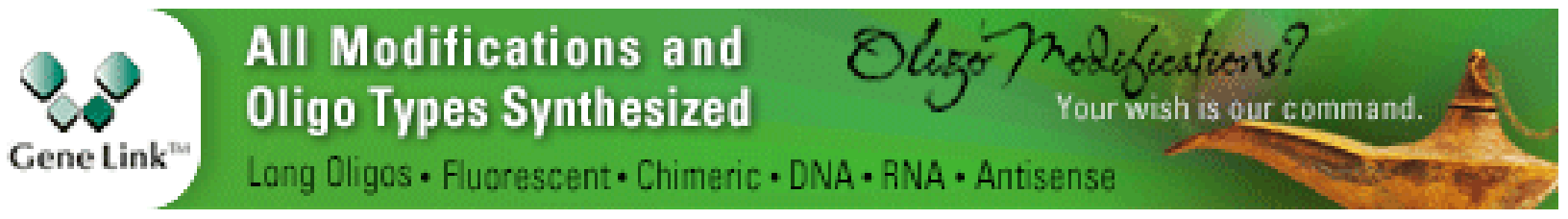

Copyright @ 2010 Cold Spring Harbor Laboratory Press; all rights reserved 